\title{
Expression of NRF2 and NRF2-modulated genes in peripheral blood leukocytes of bladder cancer males
}

\author{
E. RESZKA ${ }^{1, \star}$, Z. JABLONOWSKI ${ }^{2}$, E. WIECZOREK ${ }^{1}$, J. GROMADZINSKA ${ }^{1}$, E. JABLONSKA ${ }^{1}$, M. SOSNOWSKI ${ }^{2}$, W. WASOWICZ ${ }^{1}$ \\ ${ }^{1}$ Department of Toxicology and Carcinogenesis, Nofer Institute of Occupational Medicine, Lodz, Poland; ${ }^{2}$ I Department of Urology, Medical \\ University, Lodz, Poland \\ ${ }^{*}$ Correspondence: edyta@imp.lodz.pl
}

Received May 7, 2012/ Accepted August 1, 2012

\begin{abstract}
Nuclear factor (erythroid-derived 2)-like 2 (NRF2) is an oxidant-responsive transcription factor involved in induction of antioxidant genes. We assessed NRF2 and selected NRF2-modulated gene expression: glutathione S-transferase A1 and P1 (GSTA1 and GSTP1), mitochondrial superoxide dismutase (SOD2) in blood leukocytes of 51 bladder cancer patients and 90 control males. A significant up-regulation of SOD2 expression $(\mathrm{P}=0.002)$ was observed in leukocytes of patients. NRF2 expression was positively correlated with GSTP1 and with SOD2 mRNA level, both in patients and controls.

These data suggest disturbances in SOD2 transcription in circulating blood leukocytes of males with bladder cancer. Moreover, concomitant constitutive expression of NRF2 and its target genes may suggest important role of NRF2 transcription factor in positive regulation of antioxidant genes, resulted in enhanced cytoprotection in human peripheral blood leukocytes.
\end{abstract}

Key words: NRF2, antioxidant gene expression, bladder cancer, leukocytes

Oxidative stress, a disturbed balance between reduction and oxidation reactions, may be involved in the carcinogenic process associated with exposure to environmental carcinogens. Bladder cancer was one of the first cancer diseases to be linked to environmental carcinogens (concomitant to aniline dye manufacture, rubber and leather industries) such as heterocyclic aromatic amines, nitrites and nitrates, polycyclic aromatic hydrocarbons (PAHs), ionizing radiation, etc. [1]. Overproduction of free radicals may cause formation of oxidant DNA, protein and lipid damages and also may induce disturbances in cellular transduction pathways [2]. Antioxidant enzymes, including catalase (CAT), selenium-dependent glutathione peroxidase (GPX), selenium-independent glutathione peroxidase - glutathione S-transferase (GST) and superoxide dismutase (SOD) are involved in response to redox status alteration due to removing of specific free radicals [3]. Rodent and in vitro studies showed that a major mechanism in the defense against oxidative stress is nuclear factor (erythroid-derived 2)-like 2 (NFE2L2 or NRF2)-regulated signaling pathway, which controls the expression of target genes possessing antioxidant response element (ARE) sequence in their promoters. Under basal conditions, transcription factor NRF2 is localized in the cytoplasm and regulated by inhibitor Kelchlike ECH-associated protein 1 (KEAP1). Upon activation by oxidants and electrophiles, NRF2 is shuttled to the nucleus and recognizes ARE of various antioxidant and detoxifying genes, leading to their up-regulation. Therefore, NRF2-modulated antioxidant enzymes may protect against electrophilic agents and oxidants and may contribute to the enhancing anti-carcinogenic potential $[4,5]$.

GSTs, a large group of cytosolic and also membrane-bound enzymes, play a critical role in detoxification of electrophilic compounds, including carcinogen, drugs, and products of oxidative stress by conjugation with glutathione (GSH). GST izoenzymes are involved in detoxification of environmentally and tobacco smoke derived xenobiotics (e.g. PAHs, diolperoxides and alkylating drugs). GST isoenzymes exhibit peroxidase activity, thereby protecting the cells from reactive oxygen species and fatty acid hydroperoxides. Based on sequence homology and chromosomal location, GSTs have been divided into seven cytosolic classes: alpha (GSTA), mu (GSTM), omega (GSTO), pi (GSTP), sigma (GSTS), theta (GSTT), zeta (GSTZ); mitochondrial class kappa (GSTK) and three microsomal subfamilies (MGST) [6]. Three SOD enzymes: cellular SOD1, 
Table 1. Group characteristics

\begin{tabular}{lccc}
\hline & $\begin{array}{c}\text { Control, } \mathbf{n}=\mathbf{9 0} \\
\text { Mean } \pm \text { SD or } \mathbf{n}(\text { freq) }\end{array}$ & $\begin{array}{c}\text { Bladder cancer, } \mathbf{n}=\mathbf{5 1} \\
\text { Mean } \pm \text { SD or } \mathbf{n} \text { (freq) }\end{array}$ & P \\
\hline Age $($ years) & $58.3 \pm 1.7$ & $66.0 \pm 1.3$ & 0.002 \\
BMI $\left(\mathrm{kg} / \mathrm{m}^{2}\right)$ & $26.5 \pm 0.5$ & $26.3 \pm 0.5$ & 0.79 \\
Non-smokers & $66(73.3 \%)$ & $20(39.2 \%)$ & $<0.0001$ \\
Smokers & $24(26.7 \%)$ & $31(60.8 \%)$ & \\
\hline T1 $^{\text {a }}$ & & $44(86.3 \%)$ & \\
T2 to T4 & & $7(13.7 \%)$ & \\
G1 ${ }^{\text {b }}$ & $22(43.1 \%)$ & \\
G2 & $22(43.1 \%)$ & \\
G3 & $7(13.8 \%)$ & \\
${ }^{\text {a }}$ T - stage & & \\
${ }^{b}$ G - grade & &
\end{tabular}

mitochondrial SOD2 and extracellular SOD3 are involved in dismutation of superoxide anion $\left(\mathrm{O}_{2}{ }^{--}\right)$. Hydrogen peroxide $\left(\mathrm{H}_{2} \mathrm{O}_{2}\right)$, a product of this reaction, is further metabolized by CAT or GPXs and GSTs. SOD2 is antioxidative enzyme essential for vitality. It catalyses conversion of deriving from electron leakage from the mitochondrial electron transport chain $\mathrm{O}_{2}{ }^{-2}$ to $\mathrm{H}_{2} \mathrm{O}_{2}[7,8]$.

Antioxidative properties of GSTs and SOD2, regulated by NRF2 transcription factor, may be important in cancers of various types. GSTs protein expression and activity was extensively investigated, while SOD2 and NRF2 transcript levels have been seldom studied in urinary bladder cancer. Several studies report that urinary bladder tumors have been shown to express high levels of various GST isoenzymes compared with surrounding non-malignant uroephitelium [9-12]. Similarly, SOD2 and NRF2 was up-regulated in human bladder cancers and tumor cells $[13,14]$.

Studies on gene expression in white blood cells (WBC), as an easily accessible surrogate tissue, offers chances to obtain gene patterns in response to endo- and egzogenous stimuli. Gene expression patterns may be useful to define biological processes associated with human health and disease [15]. However, little is known of NRF2 and antioxidant genes expression in human WBC. This study investigated NRF2 and NRF2 target genes involved in defence against oxidative stress in circulating blood leukocytes of bladder cancer and control males to analyze disease-related alteration in NRF2 and antioxidant genes mRNA level. Moreover, we analyzed a possible correlation between constitutive expression of NRF2 transcription factor and its target genes in WBC of patients and controls.

\section{Patients and methods}

Urinary bladder cancer patients $(n=51)$ and controls $(\mathrm{n}=90)$, both males, were recruited from I ${ }^{\text {st }}$ Department of Urology, Medical University in Lodz and volunteers from Nofer Institute of Occupational Medicine in Lodz, respectively. Bladder cancer occurs more frequently in men than women and therefore we have decided to investigate males only. Moreover, gender is regarded as potential confounder of gene expression in human WBC [16]. All patients underwent transurethral resection and they presented non-muscle invasive bladder cancer with low T1 stage and muscle invasive bladder cancer with stage from T2 to T4. The Regional Ethics Committee for Scientific Research approved the study protocol and a written consent was obtained from each participant of the study. Venous blood samples were collected into S-Monovette ${ }^{\circledast}$ heparinized test tubes. Study participants completed a questionnaire that provided information on demographic characteristics (age, body mass index (BMI)), and smoking history. The characteristics of the study subjects is presented in Table 1.

Total RNA was isolated from whole blood using QIAamp RNA Blood Mini Kit (Qiagen). Basal expression levels of GSTA1, GSTP1, SOD2 and NRF2 in circulating blood leukocytes were determined by means of quantitative Real-Time PCR. Primers for target genes were designed with Beacon Designer 7.0 (PREMIER Biosoft International) according

Table 2. Oligonucleotides for gene expression analysis

\begin{tabular}{|c|c|c|}
\hline $\begin{array}{l}\text { Gene (size) } \\
\text { Nucleotide sequence } \\
\text { GI number }\end{array}$ & Primers $^{\mathrm{a}}$ & Amplicon size and position (nucleotides range) \\
\hline $\begin{array}{l}\text { GSTA1 (1046 bp) } \\
\text { GI: } 48375174\end{array}$ & $\begin{array}{c}\text { F TGGTTGAGATTGATGGGATGAAG } \\
\text { R TGGACATACGGGCAGAAGG }\end{array}$ & $170 \mathrm{bp}(275-444)$ \\
\hline $\begin{array}{l}\text { GSTP1 (737 bp) } \\
\text { GI: } 194363754\end{array}$ & $\begin{array}{l}\text { F ACCAGTCCAATACCATCC } \\
\text { R GCCTTCACATAGTCATCC }\end{array}$ & $175 \mathrm{bp}(220-394)$ \\
\hline $\begin{array}{l}\text { NRF2 (2884 bp) } \\
\text { GI: } 20149575\end{array}$ & $\begin{array}{l}\text { F AGCGACGGAAAGAGTATGAG } \\
\text { R TGGGCAACCTGGGAGTAG }\end{array}$ & $199 \mathrm{bp}(677-875)$ \\
\hline $\begin{array}{l}\text { SOD2 (1593 bp) } \\
\text { GI: } 67782304\end{array}$ & $\begin{array}{l}\text { F CCTGGAACCTCACATCAAC } \\
\text { R GCTGTAACATCTCCCTTGG }\end{array}$ & $129 \mathrm{bp}(265-393)$ \\
\hline $\begin{array}{l}\text { GAPDH (1310 bp) } \\
\text { GI: } 83641890\end{array}$ & $\begin{array}{l}\text { F GGACCTGACCTGCCGTCTAG } \\
\text { R TGTAGCCCAGGATGGCCCTTG }\end{array}$ & $101 \mathrm{bp}(831-931)$ \\
\hline
\end{tabular}

${ }^{\mathrm{a}} \mathrm{F}$-forward, R-reverse primer 5' - 3' 
to GenBank $^{\circledast}$ genetic sequence database (Table 2 ). The cDNA was synthesized on $250 \mathrm{ng}$ RNA with Quantitect Kit (Qiagen). Expression was quantified with FastStart SYBR Green Master (Roche) and using glyceraldehyde 3-phosphate dehydrogenase $(G A P D H)$ as the endogenous control, presenting stable expression in human circulating leukocytes. Standard curves were prepared for each gene using Universal Human Reference RNA (Stratagene) previously reverse-transcribed. All samples were amplified in triplicate. Control and cancer samples were co-amplified on the same plate.

Gene expression data were evaluated by Pfaffl method with reference gene-normalized relative quantification with efficiency correction using Q-Gene software [17], while calibrator-normalized relative expression to estimate up and down regulation for gene expression in bladder cancer group was calculated with REST 2009 Software (Version: 2.0.13).

The differences between the groups were assessed by a Mann-Whitney $U$ and t-test. The association between gene expression was computed by multivariate logistic regression and the results were adjusted for age, BMI, and smoking status. The value of $P<0.05$ was considered to reflect statistical significance, and statistical tests were two-sided. All analyses were carried out with STATA11 (StataCorp. LP) and GraphPad Prism $^{\oplus}$ Version 5.04 (GraphPad Software, Inc.) software.

\section{Results}

Urinary bladder cancer males were significantly older (66.0 \pm 1.3 years) than control males $(58.3 \pm 1.7$ years). Smokers were more prevalent among cancers than controls $(60.8 \%$ vs. $26.7 \%)$. The majority of bladder cancer patients were nonmuscle invasive characterized by low stage (T1) $(n=44,86.3 \%)$ and seven patients (13.7\%) presented muscle invasive bladder cancer. High degree of neoplasm (G) was found in twenty two (43.1\%) patients with grade $\mathrm{G} 2$ and seven patients with grade G3 (13.8\%).

All subjects expressed detectable mRNA levels in blood leukocytes with large inter-individual variations in gene expression. The highest level of gene transcripts in circulating leukocytes was observed for SOD2, while the lowest level was attributable to GSTA1 gene. Bladder cancer men presented 1.25-fold (standard error: 0.72-2.13) up-regulation of SOD2 in circulating blood leukocytes compared to control men, while GSTA1, GSTP1 and NRF2 mRNA expression was not affected by cancer disease (Table 3 ). In controls, a significantly negative relationship between expression of GSTA1, GSTP1 and NRF2 mRNA level and age $(\beta$-coefficient $=-0.00006, P=0.04 ; \beta$-coefficient $=-0.001$, $P=0.04 ; \beta$-coefficient $=-0.0009, P=0.008$, respectively) was found. Additionally, in this group BMI index was associated with a significant increase of GSTA1 expression ( $\beta$-coefficient $=0.00001, P=0.04)$. Bladder cancer patients, analyzed according to age or BMI did not show differences in GSTA1, GSTP1, SOD2 and NRF2 mRNA expression (data not shown). We observed higher expression of antioxidant genes in non-smokers than in smokers of control group, but not of bladder cancer males (Table 4). We did not observe differences in genes expression of patients with different invasiveness $\mathrm{T}$ and tumor grade $\mathrm{G}$ (data not shown). In both groups, analyzed separately and together, a significant positive relationship between mRNA level of NRF2 and SOD2 and between NRF2 and GSTP1 was found (Table 5).

\section{Discussion}

Peripheral blood leukocytes may be used as surrogate tissue instead of inaccessible tissue to analyze effects of exo-and en-

Table 3. Relative mRNA expression normalized to GAPDH ${ }^{\mathrm{a}}$ and relative mRNA expression in leukocytes of bladder cancer patients normalized to GAPDH and controls ${ }^{\mathrm{b}}$

\begin{tabular}{|c|c|c|c|c|c|c|}
\hline Gene & & Control & Bladder cancer & $P^{a}$ & $\begin{array}{c}\text { Fold change } \\
\text { (Std. error) }\end{array}$ & $P^{\mathrm{b}}$ \\
\hline \multirow[t]{4}{*}{ GSTA1 } & Median & 0.030 & 0.027 & 0.64 & 0.90 & 0.50 \\
\hline & 25\% Percentile & 0.015 & 0.016 & & $(0.31-2.82)$ & \\
\hline & $75 \%$ Percentile & 0.046 & 0.041 & & & \\
\hline & Mean \pm SD & $0.034 \pm 0.024$ & $0.032 \pm 0.022$ & & & \\
\hline \multirow[t]{4}{*}{ GSTP1 } & Median & 0.273 & 0.253 & 0.40 & 1.01 & 0.83 \\
\hline & 25\% Percentile & 0.222 & 0.227 & & $(0.66-1.57)$ & \\
\hline & 75\% Percentile & 0.329 & 0.297 & & & \\
\hline & Mean \pm SD & $0.277 \pm 0.091$ & $0.263 \pm 0.069$ & & & \\
\hline \multirow[t]{4}{*}{$N R F 2$} & Median & 0.161 & 0.165 & 0.90 & 1.03 & 0.56 \\
\hline & $25 \%$ Percentile & 0.123 & 0.132 & & $(0.66-1.59)$ & \\
\hline & 75\% Percentile & 0.205 & 0.196 & & & \\
\hline & Mean \pm SD & $0.165 \pm 0.055$ & $0.166 \pm 0.042$ & & & \\
\hline \multirow[t]{4}{*}{ SOD2 } & Median & 0.919 & 1.174 & 0.005 & 1.25 & 0.002 \\
\hline & $25 \%$ Percentile & 0.709 & 0.801 & & $(0.72-2.13)$ & \\
\hline & 75\% Percentile & 1.202 & 1.482 & & & \\
\hline & Mean \pm SD & $0.979 \pm 0.413$ & $1.186 \pm 0.409$ & & & \\
\hline
\end{tabular}


Table 4. Relative gene expression in leukocytes of bladder cancer patients and controls in relation to smoking habit

\begin{tabular}{|c|c|c|c|c|c|c|c|c|}
\hline & \multicolumn{4}{|c|}{ Control $^{\mathrm{a}}$} & \multicolumn{4}{|c|}{ Bladder cancer ${ }^{a}$} \\
\hline & Non-smokers & Smokers & \multirow{3}{*}{$\frac{\boldsymbol{\beta} \text {-coeff. }}{-0.001}$} & \multirow{3}{*}{$\frac{P}{0.05}$} & Non-smokers & Smokers & \multirow{3}{*}{$\frac{\boldsymbol{\beta} \text {-coeff. }}{0.0001}$} & \multirow{3}{*}{$\frac{\boldsymbol{P}}{0.29}$} \\
\hline & \multicolumn{2}{|c|}{ Mean \pm SD } & & & Mea & SD & & \\
\hline GSTA1 & $0.037 \pm 0.026$ & $0.026 \pm 0.017$ & & & $0.029 \pm 0.021$ & $0.034 \pm 0.024$ & & \\
\hline GSTP1 & $0.290 \pm 0.095$ & $0.243 \pm 0.073$ & -0.046 & 0.03 & $0.266 \pm 0.083$ & $0.262 \pm 0.060$ & -0.003 & 0.90 \\
\hline NRF2 & $0.172 \pm 0.054$ & $0.147 \pm 0.055$ & -0.022 & 0.07 & $0.172 \pm 0.037$ & $0.163 \pm 0.045$ & -0.015 & 0.23 \\
\hline SOD2 & $0.992 \pm 0.421$ & $0.944 \pm 0.396$ & -0.050 & 0.61 & $1.227 \pm 0.453$ & $1.159 \pm 0.383$ & -0.097 & 0.44 \\
\hline
\end{tabular}

adjusted for age and BMI

Table 5. Relationship between relative gene expression in leukocytes

\begin{tabular}{|c|c|c|c|c|c|c|}
\hline & \multicolumn{2}{|c|}{ Whole group ${ }^{a}$} & \multicolumn{2}{|c|}{ Control $^{b}$} & \multicolumn{2}{|c|}{ Bladder cancer ${ }^{b}$} \\
\hline & $\beta$-coeff. & $P$ & $\beta$-coeff. & $P$ & $\beta$-coeff. & $P$ \\
\hline GSTA1/GSTP1 & 0.0003 & 0.25 & 0.0002 & 0.41 & 0.0001 & 0.80 \\
\hline GSTA1/SOD2 & 0.00004 & 0.46 & 0.00001 & 0.84 & 0.0001 & 0.18 \\
\hline GSTA1/NRF2 & 0.005 & 0.23 & 0.0004 & 0.42 & 0.0008 & 0.33 \\
\hline GSTP1/SOD2 & 0.015 & 0.39 & 0.025 & 0.31 & 0.013 & 0.62 \\
\hline GSTP1/NRF2 & 0.429 & 0.004 & 0.408 & 0.03 & 0.471 & 0.05 \\
\hline SOD2/NRF2 & 0.056 & $<0.0001$ & 0.058 & $<0.0001$ & 0.058 & $<0.0001$ \\
\hline
\end{tabular}

adjusted for diagnosis, smoking habit, age and BMI

badjusted for smoking habit, age and BMI

dogenous stimuli on the health status [15]. In previous studies, basal expression of GSTA1, GSTP1 [18], SOD2 [16] and NRF2 [19] in human circulating WBC was detected. To add, we analyzed these genes in blood leukocytes, encompassing granular and agranular WBC. All analyzed genes presented detectable level in circulating leukocytes of examined patients, with the highest mRNA expression attributable to SOD2, followed by GSTP1, NRF2 and the lowest to GSTA1. Similarly, GSTP1 mRNA expression was most abundant among GST mRNA in human lymphocytes, followed by GSTA 1 and GSTM1, which were detectable in approximately half of analyzed samples with GSTM1 positive genotype [18].

Several studies on GSTs in urinary bladder tissues showed significantly higher activity and expression of these enzymes in bladder cancer tissues than in normal uroepithelium. Moreover, changes in GSTs have been associated with tumor stage, aggressiveness and cancer progression [9-12] and also resistance to chemotherapy [20]. GST activity was also found to be higher in the blood of bladder cancer individuals than in controls [21] and high plasma GSTA1 and GSTP1 levels were more frequently observed in urinary bladder cancer patients than in controls [22]. Up-regulation of GSTP1 in urinary bladder cancer associated with the high GSTP1 catalytic activity may also reveal high antioxidant requirements against peroxides and $\mathrm{H}_{2} \mathrm{O}_{2}$, in particular in response to elevated oxidative stress in the malignant cell. Apart from catalytic activity in detoxification of various xenobiotics, GSTP1 plays also an important role in regulation of cellular proliferation and apoptosis in the response to altered redox balance in the cells [9]. However, except of SOD2 mRNA elevated level in peripheral leukocytes of bladder cancer patients, we did not find significant differences of GSTA 1 and GSTP1 transcripts level in circulating blood leukocytes of patients and control men. Similarly, there were no differences in NRF2 mRNA expression in leukocytes in both studied groups of men. In large-scale gene expression profiling, NRF2 was up-regulated in human bladder cancer (superficial and invasive) at $92.9 \%$ when compared with normal bladder samples [14].

Although early studies have indicated suppressive function of SOD2 on cancer development, later studies showed enhanced expression of SOD2 in metastatic tumors of specific cancers [7, 8]. Highly metastatic human bladder cells displayed significantly higher SOD2 levels and activities compared with the non-metastatic parental cell line. The increase in SOD2 expression was accompanied by a significant decrease in CAT activity, resulting in a net increase in $\mathrm{H}_{2} \mathrm{O}_{2}$ production in metastactic cell line [13]. Interestingly, after the exposure of polymorphic blood mononuclear cells to $\mathrm{H}_{2} \mathrm{O}_{2}$, down-regulation of SOD2 was observed at protein level, while a large number of other redox-regulating enzymes remained unaffected [23]. This effect may point to the significance of SOD2 in redox balance alterations with decreasing SOD2 protein level used in $\mathrm{O}_{2}{ }^{-}$-removing accompanied by increasing mRNA SOD2 level for maintenance of antioxidative protection. Therefore, elevated expression of SOD2 mRNA observed in circulating leukocytes of urinary bladder cancer males may be a result of redox status alterations. 
It is widely known that genes studied in blood leukocytes exhibit differential expression dependent on sex, age, BMI and smoking [15]. We found that gene expression in circulating blood leukocytes presented inter-individual differences caused by age, smoking habit and BMI. Interestingly, these associations were observed only in non-cancer men, which may suggest alterations in white blood cell metabolism and transcription process in humans with cancer disease.

It is widely known from in vitro and rodent studies that NRF2 controls constitutive expression and followed by various electrophiles and oxidants, inducible expression of antioxidant and detoxifying enzymes, which results in enhanced cytoprotection against oxidative stress and chemical carcinogenesis $[4,5]$. NRF2 transactivates a wide variety of enzymes, including GSTA1, GSTP1 and SOD2 [24-26]. The chemically induced urinary bladder carcinogenesis in rodents showed importance of NRF2 transcripton factor in bladder cancer development [27]. However, little is known of NRF2 transcription factor and its target genes expression in human WBC, especially in cancer, including bladder cancer patients. Concomitant mRNA expression of NRF2 and SOD2 or GSTP1 observed in this study for the first time indicates the interplay between constitutive expression of NRF2 transcription factor and its two target genes in human circulating blood leukocytes. It may confirm dependence of NRF2 and antioxidant genes in peripheral human tissue, as they share biological functions under common regulatory control of NRF2 mediated signaling pathway. The positive correlation found in cancer patients and control group, suggests that regulation of constitutive SOD2 or GSTP1 gene expression by NRF2 transcription factor is not affected by cancer disease.

In conclusion, SOD2 mRNA level up-regulation in leukocytes of bladder cancer males may indicate alterations of redox status in cancer patients and importance of SOD2 in antioxidative defense. Moreover, positive association between constitutive gene expression of transcription factor NRF2 and SOD2 and also between NRF2 and GSTP1 in human circulating blood leukocytes clearly shows that interplay between NRF2 and its target genes, previously observed in rodents and in vitro studies, is a basal molecular mechanism observed under physiological conditions in healthy men and independent from pathological conditions. Studies on NRF2 and NRF2-regulated antioxidant and detoxifying enzymes at multiple steps of NRF2 signaling pathways in humans, using blood cells as a substitute target organ of action may constitute a valuable contribution to the evaluation of anticarcinogenic mechanisms and may be used for the assessment of the effects of chemotherapy in cancer disease, related with NRF2 and NRF2-modulated cytoprotective genes.

Acknowledgments: This study was financially supported by the Ministry of Science and Higher Education (1978/B/P01/2009/37) and internal grant IMP1.8/2009. Part of this work was presented in 36th FEBS Congress Biochemistry for Tomorrow's Medicine, Torino, 2011.

\section{References}

[1] VOLANIS D, KADIYSKA T, GALANIS A, DELAKAS D, LOGOTHETI $S$ et al. Environmental factors and genetic susceptibility promote urinary bladder cancer. Toxicol Lett 2010; 193: 131-137. http://dx.doi.org/10.1016/ j.toxlet.2009.12.018

[2] KLAUNIG JE, KAMENDULIS LM The role of oxidative stress in carcinogenesis. Annu Rev Pharmacol Toxicol 2004; 44: 239-267. http://dx.doi.org/10.1146/annurev.pharmtox.44.10 1802.121851

[3] LIMON-PACHECO J, GONSEBATT ME The role of antioxidants and antioxidant-related enzymes in protective responses to environmentally induced oxidative stress. Mutat Res 2009; 674: 137-147. http://dx.doi.org/10.1016/ j.mrgentox.2008.09.015

[4] KENSLER TW, WAKABAYASHI N Nrf2: friend or foe for chemoprevention? Carcinogenesis 2010; 31: 90-99. http:// dx.doi.org/10.1093/carcin/bgp231

[5] MAHER J, YAMAMOTO M The rise of antioxidant signaling - The evolution and hormetic actions of Nrf2. Toxicol Appl Pharmacol 2010; 244: 4-15. http://dx.doi.org/10.1016/ j.taap.2010.01.011

[6] NEBERT DW, VASILIOU V Analysis of the glutathione S-transferase (GST) gene family. Hum Genomics 2004; 6: 460-464.

[7] HEMPEL N, CARRICO PM, MELENDEZ JA Manganese superoxide dismutase (Sod2) and redox-control of signaling events that drive metastasis. Anticancer Agents Med Chem 2011; 11: 191-201. http://dx.doi.org/10.2174/ $\underline{187152011795255911}$

[8] KINNULA VL, CRAPO JD Superoxide dismutases in malignant cells and human tumors. Free Radic Biol Med 2004; 36 : 718-744. http://dx.doi.org/10.1016/j.freeradbiomed.2003.12 .010

[9] PLJESA-ERCEGOVAC M, SAVIC-RADOJEVIC A, DRAGICEVIC D, MIMIC-OKA J, MATIC M et al. Enhanced GSTP1 expression in transitional cell carcinoma of urinary bladder is associated with altered apoptotic pathways. Urol Oncol 2011; 29: 70-77. http://dx.doi.org/10.1016/ j.urolonc.2008.10.019

[10] SAVIC-RADOJEVIC A, MIMIC-OKA J, PLJESA-ERCEGOVAC M, OPACIC M, DRAGICEVIC D et al. Glutathione S-transferase-P1 expression correlates with increased antioxidant capacity in transitional cell carcinoma of the urinary bladder. Eur Urol 2007; 52: 470-477. http://dx.doi.org/ 10.1016/j.eururo.2007.01.046

[11] SIMIC T, MIMIC-OKA J, SAVIC-RADOJEVIC A, OPACIC M, PLJESA $\mathrm{M}$ et al. Glutathione S-transferase T1-1 activity upregulated in transitional cell carcinoma of urinary bladder. Urology 2005; 65: 1035-1040. http://dx.doi.org/10.1016/ j.urology.2005.01.005

[12] SIMIC T, SAVIC-RADOJEVIC A, PLJESA-ERCEGOVAC M, MATIC M, MIMIC-OKA J Glutathione S-transferases in kidney and urinary bladder tumors. Nat Rev Urol 2009; 1 : 281-289. http://dx.doi.org/10.1038/nrurol.2009.49

[13] HEMPEL N, YE H, ABESSI B, MIAN B, MELENDEZ JA Altered redox status accompanies progression to metastatic 
human bladder cancer. Free Radic Biol Med 2009; 46: 42-50. http://dx.doi.org/10.1016/j.freeradbiomed.2008.09.020

[14] KAWAKAMI K, ENOKIDA H, TACHIWADA T, GOTANDA T, TSUNEYOSHI K et al. Identification of differentially expressed genes in human bladder cancer through genome-wide gene expression profiling. Oncol Rep 2006; 16: 521-531.

[15] DUMEAUX V, OLSEN KS, NUEL G, PAULSSEN RH, BORRESEN-DALE AL et al. Deciphering normal blood gene expression variation - The NOWAC postgenome study. PLoS Genet 2010; 6: e1000873. http://dx.doi.org/10.1371/journal. pgen.1000873

[16] KHYMENETS O, COVAS MI, FARRE M, LANGOHR K, FITO $\mathrm{M}$ et al. Role of sex and time of blood sampling in SOD1 and SOD2 expression variability. Clin Biochem 2008; 41: 1348-1354. http://dx.doi.org/10.1016/j.clinbiochem.2008 .08 .064

[17] MULLER PY, JANOVJAK H, MISEREZ AR, DOBBIE Z Processing of gene expression data generated by quantitative real-time RT-PCR. Biotechniques 2002; 2: 1372-1379.

[18] MARIE JP, SIMONIN G, LEGRAND O, DELMER A, FAUSSAT AM et al. Glutathione-S-transferases pi, alpha, mu and mdr1 mRNA expression in normal lymphocytes and chronic lymphocytic leukemia. Leukemia 1995; 9: 1742-1747.

[19] YUBERO-SERRANO EM, GONZALEZ-GUARDIA L, RANGEL-ZUNIGA O, DELGADO-CASADO N, DELGADO-LISTA J et al. Postprandial antioxidant effect of the Mediterranean diet supplemented with coenzyme Q(10) in elderly men and women. Age 2011; doi: 10.1007/s11357-0119331-4. http://dx.doi.org/10.1007/s11357-011-9331-4

[20] HARBOTTLE A, DALY AK, ATHERTON K, CAMPBELL FC Role of glutathione S-transferase P1, P-glycoprotein and multidrug resistance-associated protein 1 in acquired doxoru- bicin resistance. Int J Cancer 2001; 92: 777-783. http://dx.doi. org/10.1002/ijc. 1283

[21] ARIKAN S, AKCAY T, KONUKOGLU D, OBEK C, KURAL AR The relationship between antioxidant enzymes and bladder cancer. Neoplasma 2005; 52: 314-317.

[22] BERENDSEN CL, MULDER TPJ, PETERS WHM Plasma glutathione S-transferase pi 1-1 and alpha 1-1 levels in patients with bladder cancer. J Urol 2000; 164: 2126-2128. http://dx.doi.org/10.1016/S0022-5347(05)66982-0

[23] HAUDEK VJ, GUNDACKER NC, SLANY A, WIMMER H, BAYER E et al. Consequences of acute and chronic oxidative stress upon the expression pattern of proteins in peripheral blood mononuclear cells. J Proteome Res 2008; 7: 5138-5147. http://dx.doi.org/10.1021/pr800438f

[24] NGUYEN PM, PARK MS, CHOW M, CHANG JH, WRISCHNIK L et al. Benzo[a]pyrene increases the Nrf2 content by downregulating the Keap1 message. Toxicol Sci 2010; 116: 549-561. http://dx.doi.org/10.1093/toxsci/kfq150

[25] SHAN Y, WANG X, WANG W, HE C, BAO Y p38 MAPK plays a distinct role in sulforaphane-induced up-regulation of ARE-dependent enzymes and down-regulation of COX-2 in human bladder cancer cells. Oncol Rep 2010; 23: 1133-1138.

[26] TAYLOR RC, ACQUAAH-MENSAH G, SINGHAL M, MALHOTRA D, BISWAL S Network inference algorithms elucidate Nrf2 regulation of mouse lung oxidative stress. PLoS Comput Biol 2008; 4: e1000166. http://dx.doi.org/10.1371/journal. pcbi. 1000166

[27] IIDA K, ITOH K, MAHER JM, KUMAGAI Y, OYASU R, et al. Nrf2 and p53 cooperatively protect against BBN-induced urinary bladder carcinogenesis. Carcinogenesis 2007; 28: 2398-2403. http://dx.doi.org/10.1093/carcin/bgm146 